\title{
Isolation and Characterization of Mevinolin Resistant Mutants of Saccharomyces cerevisiae
}

\author{
By MARTIN BARD, ${ }^{1}$ N. D. LEES, ${ }^{*}$ A. S. BURNETT ${ }^{1}$ \\ AND REX A. PARKER 2 \\ ${ }^{1}$ Department of Biology, Indiana University-Purdue University at Indianapolis, Indianapolis, \\ IN 46223, USA \\ ${ }^{2}$ Department of Biochemistry, Indiana University School of Medicine, Indianapolis, \\ IN 46223, USA
}

(Received 16 September 1987; revised 30 November 1987)

\begin{abstract}
Mutants of Saccharomyces cerevisiae resistant to mevinolin, a competitive inhibitor of 3hydroxy-3-methylglutaryl-coenzyme-A (HMGCoA) reductase (EC 1.1.1.34) were isolated and one mutant (MV71) was extensively characterized. While growth of resistant strains in the presence of mevinolin was greater than that of the wild-type strain, mevinolin at the concentration used still inhibited growth. Diploids produced by mutant/wild-type matings showed levels of mevinolin resistance which indicated incomplete dominance. Sterol synthesis in the presence of mevinolin was inhibited in strain MV71 but to a lesser degree than seen in the wild-type strain. All mevinolin resistant mutants also demonstrated a slight resistance to the antibiotic nystatin. The subcellular location of HMGCoA reductase activity in MV71 and the wild-type strain were determined and it was shown that yeast HMGCoA reductase is not regulated by a dephosphorylation mechanism as has been shown for mammalian reductases. In vivo and in vitro studies of strain MV71 and the wild-type indicated that mevinolin resistance did not result in changes in HMGCoA reductase activity as has been demonstrated in mammalian systems. Based on growth data, sterol analysis, and the lack of detection of HMGCoA reductase activity differences between strain MV71 and the wild-type, mevinolin resistance is concluded to result possibly from a mutation in $H M G 2$, one of the two functional yeast HMGCoA reductase genes, which accounts for a minor (up to $17 \%$ ) amount of total cellular reductase activity.
\end{abstract}

\section{INTRODUCTION}

The enzyme 3-hydroxy-3-methylglutaryl-coenzyme-A (HMGCoA) reductase (EC 1.1.1.34) has been extensively studied due to the fact that it is the rate-limiting enzyme in mammalian sterol biosynthesis (Brown \& Goldstein, 1980; Chin et al., 1982). Mevalonate, the product of the reaction catalysed by this enzyme, functions not only as a sterol precursor but also as a precursor of ubiquinone, dolichols, and isopentenyl tRNA. Thus, HMGCoA reductase plays an important role in a variety of essential cellular metabolic activities.

Mevinolin is an unmethylated derivative of compactin; both of these compounds have been shown to be competitive inhibitors of HMGCoA reductase (Alberts et al., 1980; Brown et al., 1978; Endo et al., 1976; Kaneko et al., 1978). Resistance to these compounds has been described in several mammalian cell lines and has been shown to involve several mechanisms, most of which result in increased reductase activity. In a baby hamster kidney cell line compactin resistance has been shown to result in a 100-fold increase in HMGCoA reductase synthesis (Hardeman et al., 1983). Subsequent investigation (Hardeman et al., 1984) indicated that the increased synthesis was due to increased HMGCoA reductase mRNA synthesis. Several

Abbreviation: HMGCoA, 3-hydroxy-3-methylglutaryl-coenzyme A. 
compactin resistant cell lines have been shown to exhibit increased HMGCoA reductase activity as a result of amplification of the reductase gene (Luskey et al., 1983; Skalnik et al., 1985). In rat hepatocyte cell lines mevinolin has been shown to decrease the rate of HMGCoA reductase degradation (Edwards et al., 1983a,b). A similar mechanism of resistance has also been reported for Chinese hamster ovary cell lines (Sinensky \& Logel, 1983).

The HMGCoA reductase from Saccharomyces cerevisiae is similar in several ways to its mammalian counterpart. It shows inhibition by the end-product sterol, ergosterol (Bard \& Downing, 1981), is sensitive to compactin (Nakamura \& Abeles, 1985), and is the rate-limiting enzyme in ergosterol biosynthesis (Kawaguchi, 1970; Quain \& Haslam, 1979). In contrast to the mammalian enzyme, the yeast enzyme is encoded by two functional genes (Basson et al., 1986). The presence of an active form of either gene is sufficient to permit normal growth, thus explaining the inability to isolate non-functional reductase mutants in this organism (Servouse et al., 1984).

Since mevinolin has potential as a cholesterol-lowering agent as well as an antifungal agent, we decided to assess the characteristics of mevinolin resistance in S. cerevisiae. In this report we describe the isolation of such mutants and demonstrate that they do not arise as the result of increased HMGCoA reductase activity.

\section{METHODS}

Chemicals. Mevinolin was the generous gift of A. Alberts of Merck Sharp \& Dohme Research Laboratories. It was used as a $20 \mathrm{mg} \mathrm{ml}^{-1}$ stock solution, which was prepared by hydrolysing the drug in ethanolic $\mathrm{NaOH}(15 \%$, $\mathrm{v} / \mathrm{v}$, ethanol, $0 \cdot 25 \% \mathrm{w} / \mathrm{v}, \mathrm{NaOH})$ at $60^{\circ} \mathrm{C}$ for $1 \mathrm{~h}$ and then filter sterilizing. Ergosterol was added from a $0.2 \%(\mathrm{w} / \mathrm{v})$ stock solution in $50 \%(\mathrm{v} / \mathrm{v})$ Tween 80 and $47.5 \%(\mathrm{v} / \mathrm{v})$ ethanol.

Organisms, mutant selection, and media. The wild-type strain of $S$. cerevisiae, A184D, has been described by Molzhan \& Woods (1972). Mutagenesis was done using ethyl methane sulphonate (50\% kill). Surviving cells were plated on yeast minimal medium $(0.67 \%$, w/v, Difco yeast nitrogen base, $2 \%$, w/v, glucose and $2 \%$, w/v, agar) containing $600-1000 \mu \mathrm{g}$ mevinolin $\mathrm{ml}^{-1}$ and incubated at $30^{\circ} \mathrm{C}$. Yeast complete medium consisted of $1 \%(\mathrm{w} / \mathrm{v})$ Difco yeast extract, $2 \%(w / v)$ Difco Bacto peptone and $2 \%(w / v)$ glucose (YEP/glucose). Yeast complete medium containing a non-fermentable energy source was identical to YEP/glucose with the exception that $3 \%(\mathrm{v} / \mathrm{v})$ glycerol replaced the glucose. Diploids were isolated by micromanipulation after crossing the appropriate strains of opposite mating type.

Determination of MIC values. Approximately $10^{5}$ cells were added to YEP/glucose solid medium (kept molten at $47^{\circ} \mathrm{C}$ ), which contained varying concentrations of mevinolin. The concentration of mevinolin which prevented any appearance of growth after $24 \mathrm{~h}$ of incubation at $30^{\circ} \mathrm{C}$ was designated the MIC.

Determination of growth yields. Flasks containing YEP/glucose were inoculated with cells to a final concentration of $10^{5}$ cells $\mathrm{ml}^{-1}$. Media supplemented with mevinolin and mevinolin plus ergosterol were prepared by adding mevinolin stock solution to a final concentration of $400 \mu \mathrm{g} \mathrm{ml}^{-1}$ and ergosterol stock solution to a final concentration of $5 \times 10^{-5} \mathrm{M}$. Control solutions without mevinolin or ergosterol were added to control media. After $48 \mathrm{~h}$ of growth at $30^{\circ} \mathrm{C}$ on a rotary shaker, cells were harvested and dry weights were determined following $48 \mathrm{~h}$ in an $80^{\circ} \mathrm{C}$ oven.

Sterol analysis. Cells were grown to exponential phase ( $100 \mathrm{Klett}$ units) or stationary phase ( $1000 \mathrm{Klett}$ units) as determined using a Klett-Summerson colorimeter with a no. 66 red filter $(640-700 \mathrm{~nm})$, at $30^{\circ} \mathrm{C}$ in yeast complete medium containing $5 \%(\mathrm{w} / \mathrm{v})$ glucose with mevinolin at a concentration of $200 \mu \mathrm{g} \mathrm{ml}^{-1}$ or with no added mevinolin. Extraction of non-saponifiable fractions and quantification of sterols has been described by Downing et al. (1980). GLC analyses were done with a Hewlett-Packard 5710A gas chromatograph using a $1 \%$ SE-30 column. Column temperature was $240{ }^{\circ} \mathrm{C}$ and nitrogen carrier gas flow rate was $45 \mathrm{ml} \mathrm{min}{ }^{-1}$. Sterols were quantified against an ergosterol standard.

Cell fractionation. Exponential phase cells were centrifuged, washed twice in $0.1 \mathrm{M}$-phosphate buffer ( $\mathrm{pH} 7.5$ ), recentrifuged, and suspended in buffer $\mathrm{A}(25 \mathrm{~mm}$-imidazole $/ \mathrm{HCl}, \mathrm{pH} 7.2,5 \mathrm{mM}$-EGTA, $200 \mathrm{mM}$-sucrose, $50 \mu \mathrm{M}$ leupeptin and $5 \mathrm{mM}$-DTT) to which 1.5 vols of acid-washed glass beads $(0.4 \mathrm{~mm})$ were added. Cells were lysed by vortexing and the lysate was centrifuged at $1000 \mathrm{~g}$ for $6 \mathrm{~min}$ to clear. The supernatant was then centrifuged at $16000 \mathrm{~g}$ for $6 \mathrm{~min}$ to yield the crude mitochondrial fraction. The $16000 \mathrm{~g}$ supernatant was ultracentrifuged at $140000 \mathrm{~g}$ for $60 \mathrm{~min}$ to obtain the microsomal and cytosolic fractions. Both the mitochondrial and microsomal precipitates were suspended in $4 \mathrm{ml}$ of buffer $\mathbf{B}(50 \mathrm{~mm}$-imidazole $/ \mathrm{HCl}, \mathrm{pH} 7 \cdot 2,1 \mathrm{mM}-\mathrm{EDTA}, 1 \mathrm{mM}$-EGTA, $20 \mu \mathrm{M}$ leupeptin and $5 \mathrm{~mm}$-DTT) and ultracentrifuged at $140000 \mathrm{~g}$ to obtain the washed mitochondrial and microsomal fractions, which were resuspended in $0.5 \mathrm{ml}$ buffer $\mathbf{B}$. 
$H M G C o A$ reductase assay. Reductase activity was determined using the radiochemical/TLC procedure described by Ingebritsen \& Gibson (1981) with the modification that $\left[{ }^{3} \mathrm{H}\right]$ mevalonolactone internal standard was added after termination of the incubations. The total reductase activity of the microsomes was determined by preincubating microsomal samples with protein phosphatase. One unit (U) of reductase activity was defined as that required for the formation of $1 \mathrm{nmol}$ of mevalonate $\min ^{-1}$. Protein concentration was determined by the method of Lowry.

Rat liver HMGCoA reductase. This was prepared as previously reported (Parker et al., 1984).

In vitro inhibition of $\mathrm{HMGCOA}$ reductase by mevinolin. Microsome samples (approx. $45 \mu \mathrm{g}$ protein for yeast and 85 $\mu \mathrm{g}$ protein for rat liver) were preincubated with varying concentrations of mevinolin for $10 \mathrm{~min}$ at $37^{\circ} \mathrm{C}$. The samples were then assayed for HMGCoA reductase activity.

Nystatin resistance. Cells were grown overnight at $30^{\circ} \mathrm{C}$ in YEP/glucose. Appropriate volumes were transferred to $20 \mathrm{ml}$ fresh medium in $250 \mathrm{ml}$ nephelometer flasks to yield starting concentrations of $8-15 \mathrm{Klett}$ units (absorbance of approximately $0 \cdot 04)$. Nystatin was added from a stock solution ( $4 \mathrm{mg} \mathrm{ml}^{-1}$ in dimethylformamide). Dimethylformamide alone did not affect growth at the concentrations used in this study. Growth was monitored with a Klett-Summerson colorimeter and mean generation times were calculated. Percentage inhibitions were then calculated from these data.

\section{RESULTS AND DISCUSSION}

\section{Mutant isolation and determination of mevinolin resistance}

Mutagenesis and selection for mevinolin resistance resulted in the isolation of approximately 200 colonies from two experiments. The resistant strains were found to be resistant to the same concentration of mevinolin on yeast complete medium containing either glucose or glycerol. Thus, resistance was confirmed in both fermentative and respiratory metabolism.

Table 1 shows growth yields of four mevinolin resistant strains and the wild-type parental strain on YEP/glucose and the same medium supplemented with mevinolin $\left(400 \mu \mathrm{g} \mathrm{ml}^{-1}\right)$ either alone or plus ergosterol $\left(5 \times 10^{-5} \mathrm{M}\right)$. MV71 was clearly the most resistant strain, with a cell yield of $53.2 \%$ of that of the control, as compared to the wild-type where the yield was only $1.6 \%$ of the control. Supplementation with ergosterol increased yields, ranging from 71 to $88 \%$ of the control levels for the mutant strains but only $18 \%$ of the control levels for the wild-type. These data indicate that mevinolin still had a significant inhibitory effect on the reductase enzyme of the mutant strains since their growth yields were reduced by 47 to $75 \%$ in the presence of mevinolin. Ergosterol supplementation did not completely restore normal growth yields, presumably due to the reduced levels of mevalonate, which serves as a precursor of other essential end products such as ubiquinone, isopentenyl tRNA, and dolichols. An alternative explanation for the inability of ergosterol supplementation to confer wild-type growth would be that ergosterol uptake is incomplete in these strains. It was also noted that growth yields for the mutant strains were less than those obtained for the wild-type, when grown in control medium. This effect is understandable since mevinolin is a competitive inhibitor of HMGCoA reductase, and a mutation conferring resistance might easily modify reductase activity or its regulation. Wildtype cells were concluded to be producing very low levels of mevalonate in the presence of mevinolin. This was based on the observation that ergosterol supplementation increased the

\section{Table 1. Growth yields of wild-type and resistant strains in YEP/glucose medium containing mevinolin or mevinolin plus ergosterol}

The values shown are the means $\pm S D$ for three independent determinations; the numbers in parentheses indicate the percentage of the control yield.

Cell yield (mg dry wt $\mathrm{ml}^{-1}$ )

\begin{tabular}{llcr}
\cline { 2 - 4 } Strain & \multicolumn{1}{c}{ Mevinolin } & Mevinolin + ergosterol & \multicolumn{1}{c}{ Control } \\
A184D & $0.18 \pm 0.05(1.6)$ & $1.98 \pm 0.73(17.9)$ & $11.04 \pm 0.04$ \\
MV1 & $2.98 \pm 0.05(30.7)$ & $7.30 \pm 0.80(75 \cdot 2)$ & $9.71 \pm 0.70$ \\
MV2 & $2.26 \pm 0.17(24.7)$ & $7.35 \pm 0.55(80.2)$ & $9.16 \pm 0.45$ \\
MV7 & $2.50 \pm 0.10(33.5)$ & $5.35 \pm 0.73(71 \cdot 7)$ & $7.46 \pm 0.31$ \\
MV71 & $4.48 \pm 0.30(53.2)$ & $7.43 \pm 0.23(88.2)$ & $8.42 \pm 0.17$
\end{tabular}


Table 2. Growth yields of mutant/wild-type diploids in YEP/glucose medium containing mevinolin

The values shown are the means \pm SD for three independent determinations except for the MV1/A184D diploid, where the value was derived from six independent determinations.

\begin{tabular}{|c|c|c|}
\hline \multirow[b]{2}{*}{ Strain } & \multicolumn{2}{|c|}{ Cell yield (mg dry wt $\mathrm{ml}^{-1}$ ) } \\
\hline & Mevinolin & Control \\
\hline AV1/A184D & $1.06 \pm 0.50$ & $10.37 \pm 0.25$ \\
\hline MV2/A184D & $1.68 \pm 0.46$ & $9.37 \pm 0.27$ \\
\hline MV7/A184D & $2.21 \pm 0.40$ & $9.20 \pm 0.45$ \\
\hline MV71/A184D & $2.94 \pm 0.34$ & $9.76 \pm 0.48$ \\
\hline A184D/A184D & $0.13 \pm 0.04$ & $10.29 \pm 0.24$ \\
\hline
\end{tabular}

Table 3. Total sterol accumulation in strains A184D and MV71 grown to late exponential or late stationary phase in the presence or absence of mevinolin

The values shown are expressed as mg total sterols per $100 \mathrm{mg}$ dry wt of cells and are the means of two independent determinations (individual values are given in parentheses), except for the exponential phase cells grown in the absence of mevinolin, which are the means \pm SD of four independent determinations.

$\begin{array}{llcc}\text { Growth phase } & \text { Strain } & \text { Additions to media } & \begin{array}{c}\text { Percentage sterol } \\ \text { content }\end{array} \\ \text { Exponential } & \text { A184D } & - & 1 \cdot 58 \pm 0 \cdot 08 \\ & \text { MV71 } & - & 1 \cdot 31 \pm 0 \cdot 14 \\ \text { A184D } & \text { Mevinolin } & 0 \cdot 21(0 \cdot 20,0 \cdot 22) \\ \text { MV71 } & \text { Mevinolin } & 0 \cdot 34(0 \cdot 32,0 \cdot 35) \\ \text { Stationary } & \text { A184D } & - & 2 \cdot 19(2 \cdot 11,2 \cdot 27) \\ & \text { MV71 } & - & 2 \cdot 11(2 \cdot 04,2 \cdot 18) \\ & \text { A184D } & \text { Mevinolin } & 0 \cdot 27(0 \cdot 25,0 \cdot 29) \\ & \text { MV71 } & \text { Mevinolin } & 0.34(0 \cdot 33,0 \cdot 35)\end{array}$

growth yield from 1.6 to $17.9 \%$ of the control. This would not occur without trace amounts of mevalonate for synthesis of the other essential end products. A similar observation has been reported in mammalian systems (Kaneko et al., 1978).

Table 2 shows the growth yields of diploids produced by matings between each of the mutant strains and the wild-type strain. Growth yields on the control medium of mutant/wild-type diploids resulted in values within $10 \%$ of the value for the wild-type diploid. In the presence of mevinolin, the mutant/wild-type diploids showed incomplete dominance. All values were significantly greater than that of the wild-type diploid but somewhat less than that for the haploid mutants (Table 1).

Since MV71 demonstrated the greatest level of mevinolin resistance, further analyses of this strain and the wild-type strain were initiated in order to characterize more fully the nature of the mevinolin-resistance mutation. The MIC values for the wild-type and MV71 strains were $200 \mu \mathrm{g}$ $\mathrm{ml}^{-1}$ and $>800 \mu \mathrm{g} \mathrm{ml}^{-1}$ respectively. The value for MV71 was an estimate since mevinolin was insoluble at higher concentrations. MV71 was crossed to A184D and diploids were isolated and sporulated. Tetrad analysis (seven tetrads) gave 2:2 segregation for resistance : sensitivity on $\mathrm{YEP} / \mathrm{glucose}$ medium containing $1000 \mu \mathrm{g}$ mevinolin $\mathrm{ml}^{-1}$, indicating mutation at a single gene locus.

\section{Sterol analysis}

The sterol levels accumulated by MV71 and the wild-type, A184D, were examined to assess the effects of the HMGCoA reductase mutation on sterol synthesis in the presence and absence of mevinolin. Table 3 shows the results of this analysis in exponential and stationary phase cultures of both strains. As was reflected in the growth yield studies (Table 1) exponential 
Table 4. Growth characteristics of wild-type and mevinolin resistant strains in the presence of nystatin

The values shown are the means \pm SD of three to eight independent determinations; the numbers in parentheses are the percentage inhibitions as compared to the control value.

\begin{tabular}{|c|c|c|c|c|}
\hline \multirow[b]{3}{*}{ Strain } & \multicolumn{4}{|c|}{ Mean generation time $(\mathrm{min})$} \\
\hline & \multicolumn{4}{|c|}{ Nystatin $\left(\mathrm{mg} \mathrm{l}^{-1}\right)$ : } \\
\hline & 0 & 0.25 & 0.50 & $1 \cdot 0$ \\
\hline A184D & $94 \cdot 9 \pm 11 \cdot 1$ & $107 \cdot 3 \pm 9.4(12.5)$ & $113.6 \pm 9.9(16.4)$ & $174 \cdot 8 \pm 34 \cdot 8(45 \cdot 1)$ \\
\hline MV1 & $103.7 \pm 8.2$ & $114.8 \pm 8.9(9.7)$ & $114.6 \pm 7.6(9.5)$ & $143.3 \pm 13.7(27.6)$ \\
\hline MV2 & $100 \cdot 0 \pm 16.1$ & $109.3 \pm 9.5(8.5)$ & $114.3 \pm 9.3(12.5)$ & $157.7 \pm 22.1(36.6)$ \\
\hline MV7 & $96.9 \pm 5.1$ & $102.5 \mp 7.5(5.5)$ & $107.5+7.2(9.9)$ & $122.0 \mp 13.1(20.6)$ \\
\hline MV71 & $101.8 \pm 10.9$ & $99 \cdot 0 \pm 10 \cdot 8(0)$ & $115.0 \pm 9.5(11.5)$ & $128.9 \pm 20.5(20.5)$ \\
\hline
\end{tabular}

cultures of MV71 produced less total sterol than did wild-type cultures when grown under control conditions, again indicating a less efficient reductase in MV71. The addition of mevinolin resulted in a significant inhibition of sterol synthesis in both strains. The sterol accumulation value of the wild-type was only $0.21 \%$ of total cell dry weight. This value may be the minimal level of sterol needed to support growth. Taylor \& Parks (1981) have demonstrated that yeast mutants requiring ergosterol as a growth factor accumulate up to $0 \cdot 2 \%$ of their dry weight as sterol. Although strain MV71 also showed a sharp decline in sterol synthesis in the presence of mevinolin $(0.34 \%$ of total cell dry weight $)$, significantly, the accumulation was still $60 \%$ above the minimal value seen in the wild-type. The sterol profiles of both strains grown in control medium were qualitatively similar. Both strains accumulated zymosterol, ergosterol and an ergostadiene precursor (ergosta-5,7-dienol and/or ergosta-7,22-dienol; Lees et al., 1984). The relative amounts of the individual sterols were proportional in the two strains.

\section{Nystatin resistance of mevinolin resistant mutants}

Since the strain MV71 contained slightly less ergosterol than the wild-type in control medium it was of interest to determine whether these strains could be distinguished experimentally on the basis of nystatin resistance. Previous work with other ergosterol-producing strains of $S$. cerevisiae (Lees et al., 1984) containing varying levels of ergosterol showed that such strains displayed different sensitivities to nystatin, a fungicidal polyene antibiotic that interacts with ergosterol (Kinsky, 1970). In addition, nystatin sensitivity was considered an important parameter in the event that mevinolin is used as an antifungal agent and resistance appears clinically. Table 4 shows the inhibitory effects of nystatin on four mevinolin resistant strains and on the wild-type strain. The sensitivity level of the wild-type was similar to that reported for other wild-type strains of $S$. cerevisiae (Lees et al., 1984). The inhibition levels shown for the mutant strains, especially those at a nystatin concentration of $1 \mathrm{mg}^{-1}$, indicate that they all have a slight resistance to the antibiotic.

\section{$H M G C o A$ reductase assays}

In order to determine whether mevinolin resistance was due to an increase in HMGCoA reductase activity, microsomal reductase activities from late exponential phase cultures of wildtype and MV71 were assayed. For cultures grown in the absence of mevinolin, the mean reductase activities resulting from three independent preparations of enzyme were $13 \cdot 3 \mathrm{U} \mathrm{mg}^{-1}$ and $15.9 \mathrm{U} \mathrm{mg}^{-1}$ for MV71 and the wild-type, respectively. Since there was no significant difference under control conditions, the assay was repeated with cultures grown in the presence of mevinolin. Activity values of $8.67 \mathrm{U} \mathrm{mg}^{-1}$ and $8.24 \mathrm{U} \mathrm{mg}^{-1}$ for MV71 and the wild-type, respectively, were obtained, again indicating no significant difference in enzyme activity.

Since yeast mitochondria have been reported to contain HMGCoA reductase activity (Trocha \& Sprinson, 1976) the relative subcellular distributions of the reductase from the wildtype and MV71 strains were examined. The data presented in Table 5 show that the relative 
Table 5. Subcellular distribution of $H M G C o A$ reductase activity in strains $M V 71$ and A184D

\begin{tabular}{lcc}
\multirow{2}{*}{ Fraction } & $\overbrace{\text { Strain A184D }}^{\left.\begin{array}{c}\text { HMGCoA reductase activity } \\
{[\mathrm{U}(\mathrm{mg} \text { protein) }}\end{array}{ }^{-1}\right]}$ \\
Cytosol & $0 \cdot 63$ & Strain MV71 \\
Mitochondria & $14 \cdot 7$ & $1 \cdot 22$ \\
Microsomes & $21 \cdot 1$ & $13 \cdot 0$ \\
Phosphatase-treated microsomes & $21 \cdot 2$ & $19 \cdot 4$ \\
& & 20.5
\end{tabular}

Table 6. Inhibition of $M V 71$ and A184D microsomal HMGCoA reductase activity by mevinolin in vitro

$\begin{array}{lccc}\begin{array}{c}\text { Source of } \\ \text { microsomes }\end{array} & \begin{array}{c}\text { Mevinolin } \\ \text { concn (nM) }\end{array} & \begin{array}{c}\text { HMGCoA reductase } \\ \text { activity } \\ \text { (mU per assay) }\end{array} & \begin{array}{c}\text { Percentage } \\ \text { inhibition }\end{array} \\ \text { Rat liver } & 0 & 809 & \\ & 30 & 144 & 82 \\ \text { A184D } & 100 & 60 & 93 \\ \text { (No mevinolin) } & 0 & 420 & 77 \\ & 30 & 128 & 91 \\ \text { A184D } & 100 & 49 & 60 \\ \text { (+ mevinolin)* } & 0 & 330 & 79 \\ & 30 & 87 & 77 \\ \text { MV71 } & 100 & 46 & 92 \\ \text { (No mevinolin) }^{*} & 0 & 957 & 70 \\ \text { MV71 } & 30 & 33 & 86 \\ \text { (+ mevinolin)* } & 100 & 212 & \end{array}$

* Mevinolin $\left(200 \mu \mathrm{g} \mathrm{ml}^{-1}\right)$ present in growth medium.

amounts of reductase activity in the various subcellular locations were identical in both strains. In addition, in order to determine whether the reductases in the wild-type and MV71 strains varied in the proportion of active and inactive forms, microsomes from both strains were activated by dephosphorylation (Ingebritson \& Gibson, 1981) prior to assay. The phosphatasetreated microsomes showed no increase in reductase activity over the controls, indicating that the reductases from both strains were fully activated in control preparations. This confirms the observation of H. J. Harwood and V. W. Rodwell (personal communication) that yeast HMGCoA reductase is not regulated by a dephosphorylation mechanism, which is in contrast to the mammalian enzyme.

Finally, the effect of mevinolin on in vitro inhibition of microsomal reductase was determined. Reductase activity from MV71 grown in the presence or absence of mevinolin was inhibited to approximately the same degree as the enzyme activity from the wild-type strain grown under the same conditions (Table 6). The same level of inhibition was also noted in a preparation of rat liver $\mathrm{HMGCoA}$ reductase.

Resistance to mevinolin in strain MV71 of $S$. cerevisiae clearly results from a mechanism unrelated to an increase in reductase activity. Whether strain MV71 is altered in other aspects of sterol biosynthesis regulation such as up-regulation of $\mathrm{HMGCoA}$ synthase is not known (Luskey et al., 1983). It is possible that the plasma membrane of MV71 is less permeable to mevinolin than the membrane of the wild-type strain. Tsujita et al. (1986) have reported that in certain rat tissues a hydroxylated compactin derivative, CS-514, was excluded from cellular uptake while compactin itself entered freely. The possibility also exists for mevinolin exclusion from specific 
subcellular compartments which contain reductase. However, the permeability mechanisms to explain resistance become less plausible in view of the partial dominance shown in the mutant/wild-type diploids (Table 2). An alternative explanation, which is consistent with the observations of Basson et al. (1986) that $S$. cerevisiae shows normal growth when either one of the two reductase genes is non-functional, is that mevinolin resistance is the result of a mutation in one of the two genes. From the data presented here, the likely candidate would be the gene $H M G 2$, whose gene product accounts for only a maximum of $17 \%$ of total cellular reductase activity. These investigators demonstrated that a strain in which the $H M G 2$ gene is disrupted contained $17 \%$ of wild-type reductase activity whereas a strain in which the $H M G 1$ gene was disrupted contained slightly higher activity $(9 \%)$ than the wild-type. A mutation conferring mevinolin resistance in $H M G 2$ would be expected to result in a strain with near normal growth characteristics in the absence of mevinolin and a significantly reduced growth in the presence of mevinolin, since at least $83 \%$ of the total reductase activity provided by $H M G I$ would be mevinolin sensitive. Mevinolin resistance due to an alteration in $H M G 2$ would also be expected to show incomplete dominance in diploids and, in the presence of mevinolin, reduced amounts of sterol would be produced, again due to the prevalence of the HMGl gene product. Data consistent with these expectations are presented in Tables 1, 2, and 3. The inability to detect in vivo and in vitro differences in reductase activity in MV71 and wild-type strains is likely to be due to the fact that the resistant form of the enzyme present in strain MV71 is a minor contributor to the total reductase activity of the cell.

This work was supported in part by a grant from the Merck Sharp \& Dohme Research Laboratories to M. B. We also wish to thank Mr A. Alberts for his support of this project. R. A. P. is presently affiliated with Bristol-Myers Pharmaceutical Research and Development Division and gratefully acknowledges their support. We thank Deborah Copple for her critical review of the manuscript.

\section{REFERENCES}

Alberts, A. W., Chen, J., Kuron, G., Hunt, V., Huff, C., Hoffman, C., Rothrock, J., Lopez, M., Joshua, H., Patchett, A., Monaghan, R., Currie, S., Stapley, E., Albers-Schonberg, G., HirschFIELD, J., HOOGSTEEN, K., LiesCh, J. \& SPRINGER, J. (1980). Mevinolin: a highly potent competitive inhibitor of hydroxymethylglutaryl-coenzyme A reductase and a cholesterol-lowering agent. Proceedings of the National Academy of Sciences of the United States of America 77, 3957-3961.

Bard, M. \& Downing, J. F. (1981). Genetic and biochemical aspects of yeast sterol regulation involving 3-hydroxy-3-methylglutaryl coenzyme $\mathrm{A}$ reductase. Journal of General Microbiology 125, 415-420.

Basson, M. E., Thorsness, M. \& Rine, J. (1986). Saccharomyces cerevisiae contains two functional genes encoding 3-hydroxy-3-methylglutaryl coenzyme A reductase. Proceedings of the National Academy of Sciences of the United States of America 83, 5563-5567.

Brown, M. S. \& Goldstein, J. L. (1980). Multivalent feedback regulation of $\mathrm{HMGCoA}$ reductase, a control mechanism coordinating isoprenoid synthesis and cell growth. Journal of Lipid Research 21, 505517.

Brown, M. S., Faust, J. R. \& Goldstein, J. L. (1978). Induction of 3-hydroxy-3-methylglutaryl coenzyme A reductase activity in human fibroblasts incubated with compactin (ML-236B), a competitive inhibitor of the reductase. Journal of Biological Chemistry 253, 1121-1128.
Chin, D. J., Luskey, K. L., Anderson, R. G. W., Faust, J. R., Goldstein, J. L. \& Brown, M. S. (1982). Appearance of crystalloid endoplasmic reticulum in compactin-resistant Chinese hamster cells with a 500-fold increase in 3-hydroxy-3methylglutaryl coenzyme A reductase. Proceedings of the National Academy of Sciences of the United States of America 79, 1185-1189.

Downing, J. F., Burrows, L. S. \& Bard, M. (1980). The isolation of two mutants of Saccharomyces cerevisiae which demonstrate increased activity of 3hydroxy-3-methylglutaryl coenzyme $\mathrm{A}$ reductase. Biochemical and Biophysical Research Communications 94, 974-979.

Endo, A., Kuroda, M. \& Tanzawa, K. (1976). Competitive inhibition of 3-hydroxy-3-methylglutaryl coenzyme A reductase by ML-236 and ML-236B, fungal metabolites having hypocholesterolemic activity. FEBS Letters 72, 323-326.

EdWards, P. A., Lan, S. F. \& Fogelman, A. M. $(1983 a)$. Alteration in the rates of synthesis and degradation of rat liver 3-hydroxy-3-methylglutaryl coenzyme A reductase produced by cholestyramine and mevinolin. Journal of Biological Chemistry 258, 10219-10222.

Edwards, P. A., Lan, S. F., Tanaka, R. \& Fogelman, A. $(1983 b)$. Mevalonalactone inhibits the rate of synthesis and enhances the rate of degradation of 3hydroxy-3-methylglutaryl coenzyme A reductase in rat hepatocytes. Journal of Biological Chemistry 258, 7272-7275. 
Hardeman, E. C., Jenke, H. S. \& Simoni, R. D. (1983). Overproduction of a $M_{\mathrm{T}} 92,000$ protomer of 3hydroxy-3-methylglutaryl-coenzyme A reductase in compactin-resistant $\mathrm{C} 100$ cells. Proceedings of the National Academy of Sciences of the United States of America 80, 1516-1520.

HaRdeman, E. C., ENDO, A. \& Simoni, R. D. (1984). Effects of compactin on the levels of 3-hydroxy-3methylglutaryl-coenzyme A reductase in compactinresistant $\mathrm{Cl} 00$ and wild type cells. Archives of Biochemistry and Biophysics 232, 549-561.

INGEBRITSEN, T. S. \& Gibson, D. M. (1981). Assay of enzymes that modulate 3-hydroxy-3-methylglutaryl$\mathrm{CoA}$ reductase by reversible phosphorylation. Methods in Enzymology 71, 486-497.

KaneKo, I., Hazama-Shimada, Y. \& Endo, A. (1978). Inhibitory effects on lipid metabolism in cultured cells of ML-236B, a potent inhibitor of 3-hydroxy-3methylglutaryl coenzyme A reductase. European Journal of Biochemistry 87, 313-321.

KaWAGUCHI, A. (1970). Control of ergosterol biosynthesis in yeast. Journal of Biochemistry 67, 219-227.

KINSKY, S. C. (1970). Antibiotic interaction with model membranes. Annual Review of Pharmacology 10, 119-142.

LeEs, N. D., Kemple, M. D., Barbuch, R. J., Smith, M. A. \& BARD, M. (1984). Differences in membrane order parameter and antibiotic sensitivity in ergosterol-producing strains of Saccharomyces cerevisiae. Biochimica et biophysica acta 776, 105-112.

LuSkeY, K. L., FAust, J. R., ChIN, D. J., BROWN, M. S. \& GoldsteIn, J. L. (1983). Amplification of the gene for 3-hydroxy-3-methylglutaryl coenzyme A reductase, but not for the $53-\mathrm{kDa}$ protein in UT-1 cells. Journal of Biological Chemistry 258, 8462-8469.

Molzhan, S. W. \& Woods, R. A. (1972). Polyene resistance and the isolation of sterol mutants in Saccharomyces cerevisiae. Journal of General Microbiology 72, 339-348.

NAKamura, C. E. \& Abeles, R. H. (1985). Mode of interaction of 3-hydroxy-3-methylglutaryl coenzyme A reductase with strong binding inhibitors : compactin and related compounds. Biochemistry 24, 1364 1376.
Parker, R. A., Miller, S. J. \& Gibson, D. A. (1984). Phosphorylation of microsomal HMG-CoA reductase increases susceptibility to proteolytic degradation in vitro. Biochemical and Biophysical Research Communications 125, 629-635.

Quain, D. E. \& Haslam, J. M. (1979). The effects of catabolite repression on the accumulation of steryl esters and the activity of $\beta$-hydroxymethylglutarylCoA reductase in Saccharomyces cerevisiae. Journal of General Microbiology 111, 343-351.

Servouse, M., Mons, N., Baillargeat, J. L. \& KARST, F. (1984). Isolation and characterization of yeast mutants blocked in mevalonic acid formation. Biochemical and Biophysical Research Communications 123, 424-430.

SINENSKY, M. \& LOGEL, S. (1983). Inhibition of degradation of 3-hydroxy-3-methylglutaryl coenzyme A reductase by mevinolin. Journal of Biological Chemistry 258, 8547-8549.

Skalnik, D. G., Brown, D. A., Brown, P. C., Friedman, R. L., Hardeman, E. C., Schimke, R. T. \& Simoni, R. D. (1985). Mechanisms of 3-hydroxy-3methylglutaryl coenzyme A reductase overaccumulation in three compactin-resistant cell lines. Journal of Biological Chemistry 260, 1991-1994.

TAYLOR, F. R. \& PARKs, L. W. (1981). An assessment of the specificity of sterol uptake and esterification in Saccharomyces cerevisiae. Journal of Biological Chemistry 256, 13048-13054.

Trocha, P. J. \& SPRinson, D. B. (1976). Location and regulation of early enzymes of sterol biosynthesis in yeast. Archives of Biochemistry and Biophysics 174, 45-51.

Tsujita, Y., Kuroda, M., Shimada, Y., Tanzawa, K., ARaI, M., KaneKo, I., TANaKa, M., Masuda, H., Tarumi, C., Watanabe, Y. \& Fuji, S. (1986). CS514, a competitive inhibitor of 3-hydroxy-3-methylglutaryl coenzyme $A$ reductase: tissue-selective inhibitor of sterol synthesis and hypolipidemic effect on various animal species. Biochimica et biophysica acta 877, 50-60. 